\title{
"O HOMEM É MESMO A SUA TESTOSTERONA": PROMOC̄̃OO DA ANDROPAUSA E REPRESENTACÕES SOBRE SEXUALLDADE E ENVELHECIMENTO NO CENÁRIO BRASILEIRO
}

\author{
Fabíola Rohden \\ Universidade Federal do Rio Grande do Sul - Brasil
}

Resumo: $O$ artigo trata da construção recente de novos diagnósticos médicos e de um correspondente mercado consumidor em potencial considerando o caso do distúrbio androgênico do envelhecimento masculino ou andropausa, "doença" que afetaria os homens a partir dos 35-40 anos de idade. A perspectiva utilizada centra-se nos estudos sociais da ciência e gênero e particularmente na necessidade de investigar as redes criadas no processo de construção dessa nova categoria. Por meio da análise da produção científica e da trajetória da construção da andropausa como fenômeno de interesse público, elabora-se um processo inédito de medicalização do homem e da sexualidade masculina, via o reforço na centralidade dos hormônios como modelo preponderante de entendimento corporal. Além disso, destaca-se a promoção de uma intrincada conexão simbólica que associa juventude, saúde, beleza e atividade sexual nos processos de patologização das fases ou de condições de vida e na recusa do envelhecimento.

Palavras-chave: andropausa, masculinidade, medicalização, testosterona.

\begin{abstract}
The article deals with the recent construction of new medical diagnoses and a corresponding potential consumer market by considering the case of Androgen Disorders of the Male Aging, or Andropause, "disease" that supposedly affected men from 35-40 years old. The approach used focuses on the social studies of science and gender and in particular the need to investigate the networks created in the process of the construction of this new category. Through the analysis of scientific production and the trajectory of construction of Andropause as a phenomenon of public interest, an unprecedented process of medicalization of men and male sexuality is enacted, by strengthening the centrality of hormones as predominant model for understanding the body. Moreover, there is the promotion of an intricate symbolic connection that links youth, health, beauty and sexual activity in the pathologization of the phases or conditions of life and the refusal of aging.
\end{abstract}

Keywords: andropause, masculinity, medicalization, testosterone. 


\section{Introducão}

Este trabalho trata do problema da construção recente de novos diagnósticos médicos e de um correspondente contingente consumidor em potencial considerando o caso do surgimento do distúrbio androgênico do envelhecimento masculino (DAEM) ou andropausa. Trata-se de uma "doença" que afetaria os homens a partir dos 35-40 anos de idade caracterizada pela perda da libido ou desejo sexual, diminuição de massa muscular, perda de energia, depressão, disfunção erétil entre outros sintomas, tendo como causa o decréscimo na produção da testosterona. ${ }^{1}$

A hipótese a ser discutida aqui é a de que nas duas últimas décadas tem se assistido à configuração de um novo modelo de representações acerca do envelhecimento masculino no qual se privilegia a dimensão da sexualidade. Tanto nos veículos de comunicação de massa quanto nas publicações científicas cresce enormemente o espaço dedicado a tratar desses temas que, em geral, vêm associados a uma suposta necessidade de reposição hormonal. Embora uma certa perspectiva crítica apareça, sobretudo com a divulgação de dados que colocam em xeque a eficácia e a segurança de tais terapias, pode-se supor que o imperativo da reposição hormonal tem prevalecido, tanto na prática médica quanto nas representações leigas que vêm se consolidando.

Até recentemente as mulheres tinham sido um foco muito mais recorrente nos discursos sobre esse corpo hormonal, tanto no âmbito científico quanto na divulgação mais ampla. Fenômenos como a tensão pré-menstrual (TPM) ou as transformações percebidas com a menopausa têm sido usadas como chaves explicativas para as mais variadas formas de comportamento e têm também alimentado uma grande indústria de tratamento dos "problemas femininos". A novidade agora é que, com o discurso em torno do DAEM, os homens também passam a ser alvos desse tipo de investimento que privilegia a associação entre hormônios, juventude, sexualidade e saúde.

\footnotetext{
Este artigo é resultado do projeto de pesquisa "Diferenças de gênero na recente medicalização do envelhecimento e sexualidade: a criação das categorias menopausa, andropausa e disfunção sexual", coordenado por mim e apoiado pelo CNPq, e se articula com o estudo Sexualidade, Ciência e Profissão, promovido pelo Centro Latino Americano em Sexualidade e Direitos Humanos (CLAM/IMS/UERJ), e coordenado por Jane Russo, a quem agradeço especialmente, além das outras integrantes da equipe, pela colaboração.
} 
Vários estudos recentes têm mostrado como os laboratórios farmacêuticos têm tido um papel importante nesse processo, influenciando as agendas de pesquisa, a formação médica e a prática da prescrição dos tratamentos. Sabe-se, por exemplo que, em muitos casos, o investimento em propaganda é maior do que na pesquisa e os novos remédios são reutilizações de substâncias já conhecidas (Angell, 2007; Fishman, 2004; Moynihan, 2010; Tiefer, 2006). Alguns autores chegam mesmo a definir a promoção e comercialização de novas doenças como casos de "disease mongering", ou seja, da execução de um conjunto de estratégias sequenciais empregadas para convencer as pessoas, não necessariamente "doentes", de que teriam problemas de saúde e de que deveriam tratá-los via o aparato médico-farmacêutico. Entre essas estratégias, destacam-se a definição de uma grande parte da população como sofrendo da doença, sua associação com problemas relativos ao conceito genérico de equilíbrio hormonal, o uso seletivo de estatísticas e de sintomas pouco indicativos, a valorização da tecnologia e a promoção de médicos experts especialmente capazes e preparados para o relacionamento com a imprensa (Payer, 1991). ${ }^{2}$

No caso específico da conjunção entre envelhecimento e sexualidade, há que se notar que a promoção das novas drogas e recursos caminha lado a lado com a promoção de modelos de comportamento centrados na valorização do corpo jovem, saudável e sexualmente ativo. E no que se refere ao caso masculino, é necessário observar as peculiaridades que começam a ser apontadas por pesquisadores como Barbara Marshall $(2007,2010)$ que, ao estudar a medicalização do que chama menopausa masculina, sugere que estaríamos assistindo a criação de novas narrativas que aproximariam os homens de mais idade de um modelo mais feminino, no sentido de mais vulneráveis e mais sujeitos às intervenções médicas, em um processo constante de "vigilância da virilidade". ${ }^{3}$ A autora propõe que a tarefa fundamental dos "estudos críticos da ciência, saúde e envelhecimento" seria investigar as estórias sobre

2 O periódico Plosmedicine em abril de 2006 publicou um número especial tratando desse tema com artigos de vários pesquisadores, como Tiefer (2006). Ver também Cassels e Moynihan (2005) e Kassirer (2005).

3 Em virtude da necessidade de limitar a circunscrição do tema e das referências aqui utilizadas, não será possível dialogar mais diretamente com os trabalhos que têm discutido a construção de diferentes masculinidades no mundo contemporâneo e aqueles que, mais recentemente, vêm chamando a atenção para a questão da saúde do homem, entre os quais se pode mencionar: Rosenfeld e Faircloth (2006), Hoberman (2005), Carrara, Russo e Faro (2009), Medrado et al. (2009), Gomes (2008), Schraiber, Gomes e Couto (2005), Azize (2004), Brigeiro (2002). 
sexualidade e envelhecimento narradas pela "imaginação farmacêutica". Trata-se de reconhecer como no processo de promoção de novos diagnósticos e tratamentos produzem-se narrativas bastante eficazes que acionam valores e representações sensíveis em determinados contextos culturais. No caso em questão, a "imaginação farmacêutica" teria sido bem sucedida ao redefinir os cursos da vida sexual em termos dos efeitos das drogas empregadas no tratamento da função sexual. A base para essa transformação seria a mudança de padrão utilizada para pensar o corpo e suas funções. O binarismo normal/ anormal teria sido substituído pelo novo funcional/disfuncional. Como exemplo, cita que, durante muito tempo, foi considerado "normal" que a função erétil ou o nível de testosterona declinassem ao longo da vida de um homem. Porém, essa ocorrência passa a ser pensada como "disfuncional", o que seria "comprovado" pela existência de tratamentos que poderiam melhorar a função em questão. Dessa forma, o "funcional" passa a ser definido pelo que é tratável. O exemplo mais evidente disso seria como o Viagra foi fundamental para instituir a própria categoria da disfunção erétil e, mais recentemente, de como a reposição de testosterona seria o marcador por meio do qual se pode redefinir a andropausa (Marshall, 2010).

Como o objetivo desse trabalho é analisar a criação de um fenômeno chamado andropausa, que envolve desde a pesquisa de ponta até a realização de exames urológicos em praça pública, passando pelo interesse dos laboratórios farmacêuticos, atenção da mídia e criação de políticas públicas, a estratégia metodológica envolve o investimento em várias frentes. Para tanto se recorre à análise de artigos de periódicos científicos, de sites de sociedades médicas, reportagens, programas de televisão e material de divulgação na imprensa, além da etnografia de congressos médicos e campanhas e realização de entrevistas. A dispersão das fontes é nesse caso imprescindível para mostrar o alcance desse processo, as intrincadas redes acionadas e também o contraste entre o discurso produzido no âmbito científico e aquele direcionado a um universo mais popular que visa exatamente à promoção do consumo de novas representações e produtos.

Esta análise se apoia nos estudos que têm procurado investigar a produção do conhecimento científico problematizando a posição, mais largamente difundida, de que seria possível distinguir e separar os fatos puramente naturais do universo dos constrangimentos sociais e da própria produção da cultura. Partindo dessa compreensão mais geral, não seria possível investigarmos 
determinados fenômenos sem lançar mão de conceitos e perspectivas que procurem dar conta da imbricação mútua entre as facetas social, política, econômica, biológica, científica, técnica e tantas outras como propõe, por exemplo, Bruno Latour (1994) ao utilizar categorias como híbridos ou redes sociotécnicas. Esse tipo de perspectiva é imprescindível na análise dos fenômenos relacionados à criação de novas doenças e diagnósticos, como já mostrava de maneira inaugural o trabalho de Ludwik Fleck (1979) sobre o caso da sífilis, publicado originalmente em 1935 e só recuperado no final dos anos 1970. No sugestivo livro Gênesis e desenvolvimento do fato científico, Fleck (1979) afirma que as explicações científicas só são produzidas e sobrevivem na medida em que se desenvolvem em conformidade com o "estilo de pensamento" predominante, ou seja o universo de possibilidades daquilo que é permitido ou o tipo particular de visão e ação que são possíveis, em determinado contexto social. Os "fatos científicos", assim como conceitos e técnicas, apenas podem existir em conformidade com o estilo de pensamento privilegiado e a partir da manutenção de um "coletivo de pensamento", ou seja, de uma comunidade de pessoas que interagem intelectualmente e que fornecem o suporte para o desenvolvimento histórico de qualquer campo intelectual.

Para além dessa perspectiva mais ampla, o estudo da produção de novas patologias também precisa acionar a discussão em torno dos processos de medicalização da sociedade que têm um de seus pilares na recente transformação, ocorrida a partir do início do século XIX, do privilégio dado não mais ao indivíduo doente mas à definição das doenças como entidades ontologicamente reais e específicas. Na medida em que as doenças, assim concebidas, tornam-se entidade sociais com as quais passamos a interagir cada vez mais quotidianamente, não é de se estranhar a importância que adquire a dimensão do diagnóstico e sua capacidade de incitar fortes tensões políticas. É o que podemos perceber quando assistimos a diferentes grupos de atores sociais, desde médicos a órgãos do governo e ativistas, em longas disputas sobre a adequação de um determinado diagnóstico. Além disso, não se pode deixar de mencionar que a operacionalização do diagnóstico torna-se peça fundamental no estabelecimento de todo o processo de cuidado terapêutico, desde a organização dos sistemas de saúde e o uso de medicamentos à correspondente burocracia associada a esses eventos (Rosenberg, 2002).

O termo "medicalização" tem sido usado por autores como Peter Conrad $(1992,2007)$ para definir o processo através do qual problemas anteriormente 
definidos como não médicos passam a ser concebidos e tratados como problemas médicos e caracterizados como doenças ou transtornos. Esse fenômeno abarcaria cada vez mais comportamentos tidos como desviantes e também processos vitais ou condições de vida, como nascimento, envelhecimento, morte, sexualidade, etc. Contudo, uma importante ressalva feita pelo autor se refere ao fato de que nem sempre os médicos são agentes centrais ou dotados de mais poder nesse jogo de interesses. Muitas vezes os próprios pacientes, inclusive, participam ativamente na busca pela medicalização institucionalizada de uma determinada condição, conferindo um caráter ainda mais complexo a esse processo sociocultural.

A partir desse enquadramento e do reconhecimento de um novo movimento de medicalização das passagens de idade para os homens e sua crescente associação com a valorização da sexualidade, procura-se, a seguir, mapear a trajetória de aparecimento da andropausa ou DAEM ${ }^{4}$ no cenário das publicações biomédicas e seu deslizamento para o âmbito da divulgação pública, com destaque para o nítido aumento dos investimentos dos laboratórios farmacêuticos no setor.

\section{Andropausa nas pesquisas e publicações biomédicas}

De acordo com Marshall (2007), principal referência sobre o tema, o chamado climatério masculino só começa a aparecer como doença orgânica e tratável a partir da década de 1930. Somente na década de 1940 inicia-se o que seria considerado o seu tratamento científico por meio da definição do hipogonadismo climatérico enquanto uma desordem clínica causada pela queda na testosterona que afetaria uma proporção relativamente pequena de homens mais velhos. A disfunção sexual já aparece como principal sintoma mas não como foco do tratamento, na medida em que era considerado problemático ou mesmo imoral promover a sexualidade em homens de mais idade. A terapia de testosterona é então utilizada com repetidas e insistentes ressalvas de que não se estaria priorizando os benefícios sexuais. Seria somente a partir dos anos 1960 que a passiva aceitação das mudanças na capacidade sexual em função

4 Será mantido o uso dos dois termos no decorrer do texto, assim como a utilização de outros, na medida em que se procura acompanhar o uso corrente no campo. 
da idade seria posta em xeque e a sexualidade se tornaria central na reconsideração da andropausa. Mas isso só ocorreria de fato nas pesquisas biomédicas na década de 1990 e já associado ao empreendimento das descobertas para tratamento da disfunção erétil.

De uma maneira geral, pode-se sugerir que esse cenário se reflete nos artigos científicos publicados sobre o tema. Por meio de uma pesquisa de referências buscando por termos como andropausa, climatério masculino, DAEM, hipogonadismo masculino tardio e similares na base da Biblioteca Virtual em Saúde (BVS), ${ }^{5}$ que congrega dados da MEDLINE - Literatura Internacional em Ciências da Saúde e LILACS - Literatura Latino-Americana e do Caribe em Ciências da Saúde, percebeu-se que, embora haja algumas referências a climatério masculino ou andropausa desde o início da catalogação dos trabalhos na MEDLINE (1966), é somente na virada para a década de 2000 que temos um número mais expressivo de artigos. Se nas décadas de 1970, 1980 e 1990 temos uma faixa mais ou menos estável no número de trabalhos, representando respectivamente 56, 39 e 50 trabalhos, já entre janeiro de 2001 e setembro de 2009, contabilizaram-se 321 publicações. A maioria desses trabalhos está inserida em revistas médicas de urologia e endocrinologia e promove desde discussões mais abrangentes sobre os referidos conceitos, e mesmo a existência ou não de andropausa ou DAEM, até a consideração de seus possíveis sintomas, tratamentos, reposição hormonal, associações com outras doenças, comparação com a menopausa e, com considerável ênfase, a associação com problemas relacionados à sexualidade, como disfunção erétil e falta de desejo.

Não é por acaso que esse expressivo aumento no número de artigos corresponde ao lançamento em âmbito internacional de um instrumento de reconhecimento e medição do DAEM. Trata-se da Escala de Sintomas do Envelhecimento Masculino (Aging Male's Symptoms Scale - AMS) originalmente desenvolvida na Alemanha em 1999 e baseada na suposição de que, assim como as mulheres no período da menopausa, os homens também desenvolveriam sintomas similares. Segundo os autores do estudo, Heinemann et al. (2003), a escala serviria para reconhecer sintomas de envelhecimento entre

5 Conforme os dados disponíveis em http://bases.bvs.br em setembro de 2009.

Horizontes Antropológicos, Porto Alegre, ano 17, n. 35, p. 161-196, jan./jun. 2011 
grupos de homens com diferentes condições, avaliar a gravidade dos sintomas no tempo e medir as mudanças pré e pós-terapia de reposição de androgênio. Foi desenvolvida a partir da análise de mais de 200 variáveis medidas em mais de 100 homens "bem caracterizados medicamente". Após as análises estatísticas, três dimensões de sintomas foram identificadas: psicológica, somato-vegetativa e sexual, que explicariam 51,6\% da variância total. De acordo com os autores, isso permitia uma redução no número de itens da escala para 17. Essa nova versão foi imediatamente aplicada para uma amostra de 992 homens alemães com a função de estabelecer os valores de referência para a severidade dos sintomas entre homens acima de 40 anos. Em seguida a escala foi traduzida para o inglês e o artigo publicado pelos autores em 2003 já disponibilizava os arquivos da AMS em 12 línguas, incentivando os interessados em fazer uso do instrumento mesmo sem a necessidade de permissão formal. Na conclusão do trabalho, afirma-se que a escala é um instrumento importante na medida em que já era utilizada em todo o mundo (Heinemann et al., 2003). Além disso, declaravam que não havia conflito de interesse na produção do estudo. ${ }^{6}$

Outra faceta importante no processo em cena é a associação produzida entre andropausa, enquanto um complexo de sintomas pouco definidos, e hipogonadismo ou deficiência androgênica, um estado bioquímico. Como salienta Marshall (2007), o uso de testosterona foi aprovado nos Estados Unidos apenas para o tratamento do hipogonadismo, e não da andropausa em si. Foi necessário então construir uma relação específica entre o hipogonadismo e a andropausa para justificar o uso de medicamentos por um novo contingente de pessoas. A autora afirma ainda que esta estratégia foi extremamente bem sucedida e que, mais do que a medicalização da andropausa, produziu-se a própria medicalização dos homens de meia-idade. Somente entre 1997 e 2002 as prescrições de testosterona, principalmente via os novos produtos transdérmicos, haviam aumentado em $400 \%$ e eram fornecidas sobretudo a homens entre 45 e 55 anos.

\footnotetext{
6 Em 2006 temos um outro artigo, cuja autoria também é encabeçada por Lothar Heinemann, destinado a atestar a capacidade clínica da escala AMS em medir efeitos do tratamento com testosterona a partir de pesquisa com 1670 homens com deficiência androgênica que foram tratados com gel de testosterona. Dessa vez, a segunda autora do artigo, Claudia Moore, declara que é empregada da companhia que produz produtos de testosterona, mas mesmo assim os autores consideram que não há conflitos de interesse na investigação e na produção dos dados (Heinemann et al., 2006).
} 


\begin{tabular}{|c|c|c|c|c|c|}
\hline $\begin{array}{l}\text { Quais dos seguintes sintomas se aplicam neste momento ao seu caso pe } \\
\text { apropriado para cada sintoma. Para os sintomas que não se aplicam ao s } \\
\text { "nenhum". }\end{array}$ & $\begin{array}{l}\text { essoal? } \\
\text { seu cas }\end{array}$ & fav & $\begin{array}{l}\text { ssinale } \\
\text { assinal }\end{array}$ & qua & \\
\hline Sintomas: & nenhum & ligeiro & moderado & grave & $\begin{array}{l}\text { muitissimo } \\
\text { grave }\end{array}$ \\
\hline & & & & & \\
\hline & & & & & \\
\hline 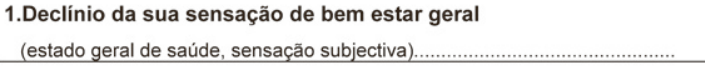 & $\square$ & $\square$ & $\square$ & $\square$ & $\square$ \\
\hline $\begin{array}{l}\text { 2.Dores nas articulaçöes e dores musculares, (dor na base das } \\
\text { costas, dor nas articulaçőes, dor num membro, dores de costas em geral)...... }\end{array}$ & $\square$ & $\square$ & $\square$ & $\square$ & $\square$ \\
\hline $\begin{array}{l}\text { 3.Sudação excessiva (episódios inesperados/súbitos de sudação, afron- } \\
\text { tamentos independentes de esforço)...... }\end{array}$ & $\square$ & $\square$ & $\square$ & $\square$ & $\square$ \\
\hline $\begin{array}{l}\text { 4.Problemas de sono (dificuldades em adormecer, dificuldades em dormir } \\
\text { toda a noite, acordar cedo e sentir-se cansado, sono agitado, insónia).............. }\end{array}$ & $\square$ & $\square$ & $\square$ & $\square$ & $\square$ \\
\hline $\begin{array}{l}\text { 5. Aumento da necessidade de dormir, sentir-se frequentemente } \\
\text { cansado. }\end{array}$ & $\square$ & $\square$ & $\square$ & $\square$ & $\square$ \\
\hline $\begin{array}{l}\text { 6. Irritabilidade (sentir-se agressivo, facilmente perturbado com pequenas } \\
\text { coisas, com humor instável). }\end{array}$ & $\square$ & $\square$ & $\square$ & $\square$ & $\square$ \\
\hline 7. Nervosismo (tensão interior, agitação, sentir-se desassossegado)................ & $\square$ & $\square$ & $\square$ & $\square$ & $\square$ \\
\hline 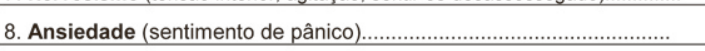 & $\square$ & $\square$ & $\square$ & $\square$ & $\square$ \\
\hline $\begin{array}{l}\text { 9. Exaustão física/Falta de vitalidade (diminuiçăo geral de performance, } \\
\text { actividade reduzida, falta de interesse em actividades de lazer, sensaçăo de produzir } \\
\text { menos, de alcançar menos, de ter de se forçar para empreender } \\
\text { actividades)....................................... }\end{array}$ & $\square$ & $\square$ & $\square$ & $\square$ & $\square$ \\
\hline 10. Diminuição da força muscular (sensação de fraqueza) ......................... & $\square$ & $\square$ & $\square$ & $\square$ & $\square$ \\
\hline $\begin{array}{l}\text { 11. Estado de espírito depressivo (sentir-se em baixo, triste, à beira das } \\
\text { lágrimas, com falta de energia, alteraçöes de humor, sensaçấo de que nada vale a } \\
\text { pena).. }\end{array}$ & $\square$ & $\square$ & $\square$ & $\square$ & $\square$ \\
\hline 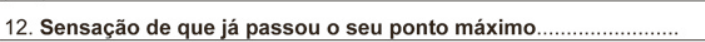 & $\square$ & $\square$ & $\square$ & $\square$ & $\square$ \\
\hline 13. Sentir-se esgotado/sentir que chegou ao ponto mais baixo....... & $\square$ & $\square$ & $\square$ & $\square$ & $\square$ \\
\hline 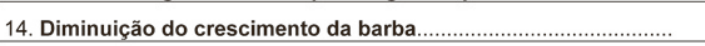 & $\square$ & $\square$ & $\square$ & $\square$ & $\square$ \\
\hline 15. Diminuição da capacidade/frequência do desempenho sexual.. & $\square$ & $\square$ & $\square$ & $\square$ & $\square$ \\
\hline 16. Diminuição do número de erecçöes matinais................................ & $\square$ & $\square$ & $\square$ & $\square$ & $\square$ \\
\hline 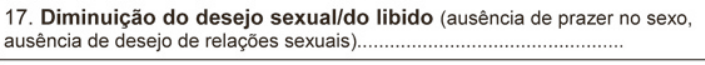 & $\square$ & $\square$ & $\square$ & $\square$ & $\square$ \\
\hline Tem mais alguns sintomas importantes? & Sim.. & $\ldots \square$ & Não..... & $\ldots \square$ & \\
\hline Se sim, por favor descreva-os & & & & & \\
\hline
\end{tabular}

Muito obrigada pela sua colaboração

Figura 1. Escala de Sintomas do Envelhecimento Masculino (Heinemann et al., 2003).

É possível sugerir que a promoção da nova nomenclatura, distúrbio androgênico do envelhecimento masculino, esteja relacionada precisamente com essa imperiosa condição de associação com o hipogonadismo. Mas, se em um 
momento inicial a deficiência androgênica mais ampla era o foco e servia para criar um quadro sintomático geral, notam-se mais recentemente novas tentativas de precisão que caminham no sentido de valorizar precisamente a testosterona. É o que se observa em artigos internacionais, como um editorial do European Urology em 2006 que advoga o uso do termo "Síndrome de Deficiência de Testosterona" (SDT), já que a " "testosterona' é claramente entendida pela comunidade médica e pelo público como representativo do principal hormônio masculino" (Morales et al., 2006, p. 408-409, tradução minha). Além disso, não carregaria a negativa e frequentemente errônea percepção de que seria restrita aos homens mais velhos, o que seria induzido pelos termos andropausa, menopausa ou climatério masculino, ou mesmo distúrbio androgênico do envelhecimento masculino.

No que se refere a artigos produzidos no Brasil, podemos citar o trabalho de revisão publicado por Bonaccorsi em 2001 que, após apresentar o que seria a andropausa, afirma que a "síndrome de insuficiência androgênica parcial" acomete pelo menos $20 \%$ a $30 \%$ dos homens a partir dos 50 a 60 anos e que a terapêutica por testosterona tem sido segura e eficaz em 30\% dos casos, não havendo provas de que aumente a morbidade e mortalidade cardio-vascular. $\mathrm{Na}$ sequencia, o autor conclui, de forma enigmática, que: "Se existem riscos inerentes às ações da testosterona, seja ela endógena ou exógena, estes riscos seriam o tributo que os homens têm que pagar para se manterem homens saudáveis." (Bonaccorsi, 2001, p. 131). Vemos aí uma peculiar correlação entre correr riscos para se manter saudável e uma clara associação entre a ideia da presença da testosterona e o "manter-se" jovem e saudável.

$\mathrm{Na}$ mesma linha identificamos outros textos dedicados a definir a nova categoria de diagnóstico, como o artigo de Cairoli (2004). O autor afirma que, apesar de há anos se reconhecer que o processo de envelhecimento no homem ocorre com o declínio progressivo na produção de androgênio, só recentemente um interesse significativo foi desenvolvido em torno da "importância do problema, que é conhecido como climatério masculino, andropausa, declínio androgênico no homem que envelhece (Androgen Decline in the Aging Male - $A D A M)$, ou, mais apropriadamente, deficiência androgênica no envelhecimento masculino (DAEM)" (Cairoli, 2004, p. 291). Acrescenta ainda que o termo andropausa "é biologicamente errado e clinicamente inapropriado, mas transmite adequadamente o conceito de mudanças emocionais e físicas que, embora relacionadas ao envelhecimento, são em geral também associadas 
com alterações hormonais significativas" (Cairoli, 2004, p. 291). Entre essas mudanças destacam-se perda de energia, depressão, diminuição da libido e disfunção erétil, que ocorreriam no homem idoso e de meia-idade com um nível de testosterona abaixo do normal. O uso da testosterona em terapias de reposição hormonal (TRHs) para prevenir ou reverter a andropausa, com os objetivos de "melhorar a libido e os aspectos psicológicos", estaria provocando cada vez maior interesse (Cairoli, 2004, p. 296).

\section{Andropausa como fenômeno de interesse público}

No que se refere à repercussão desses temas na imprensa ou mesmo a criação da andropausa como categoria culturalmente significante, é surpreendente a matéria publicada na revista Veja já em 28 de maio de 1997, com autoria de Glenda Mezarobba. ${ }^{7}$ Com o impactante título "O outono do macho: cresce o número de homens que buscam na reposição hormonal o vigor da juventude", mostra que a andropausa tem levado cada vez mais homens e procurar urologistas, endocrinologistas ou especialistas em medicina ortomolecular, principalmente nos Estados Unidos, onde 200 mil "madurões" já utilizariam a reposição. A versão masculina da menopausa, caracterizada pelo declínio na produção hormonal, afetaria 30\% dos homens entre 50 e 60 anos e por isso seria necessário reconhecer os sintomas e realizar o exame de dosagem de testosterona. Esse hormônio é apresentado como uma espécie de fonte da juventude que, além de propiciar o desenvolvimento dos caracteres sexuais masculinos, comandaria a libido. $\mathrm{O}$ tom da reportagem reproduz uma certa dúvida expressa nas diferentes posições dos especialistas entrevistados mas apenas quanto à necessidade de reposição hormonal. Há inclusive um quadro que destaca benefícios (diminuição da irritabilidade, retardo do envelhecimento, aumento da resistência a infecções, aumento da massa muscular e melhora do desempenho sexual) e riscos (ansiedade, distúrbio do sono, aumento de pelo no corpo, câncer no fígado e de próstata, atrofia testicular) da reposição. No que se refere à criação do diagnóstico prevalece a ideia de que há uma condição problemática a ser investigada e tratada, tal como afirma o

\footnotetext{
7 Para este trabalho, foi realizado um levantamento sobre andropausa e temas afins na Veja entre 1990 e 2009. Essa publicação foi priorizada por se tratar do periódico semanal de maior circulação no Brasil, cujo número de leitores é estimado em mais de 10 milhões.
} 
urologista Cristiano Santana, pesquisador da Unicamp, dizendo que "embora não ocorra interrupção total da produção de hormônios, o climatério masculino existe, e são muitos os sintomas" (Mezarobba, 1997, p. 90). A parte final é dedicada ao relato de homens que se sentiram favorecidos com a reposição e à apresentação dos tratamentos existentes, com destaque para comprimidos, injeções e adesivos transdérmicos. Estes últimos são apresentados como mais eficazes, embora com o incoveniente do alto custo. Há ainda a referência ao fato de que há oito meses o doutor Cristiano Santana vinha prescrevendo adesivos importados dos Estados Unidos e da Inglaterra. O texto termina com a menção de que agora os homens estariam sentindo "um pouquinho o gosto dos dilemas enfrentados pelas mulheres na questão de como enfrentar a menopausa" e de que o tratamento de reposição duraria a vida toda (Mezarobba, 1997, p. 92).

Se a reportagem "inaugural" de 1997 ainda deixava lugar para uma certa dúvida, a matéria de capa publicada em 13 de fevereiro de 2002, autoria de Gabriela Carelli, já indicava um outro foco. O título dessa vez era "As idades do sexo: a era pós Viagra reserva novos tratamentos para atrasar o relógio biológico de homens e mulheres e melhorar o desempenho sexual". No caso dos homens, destaca-se que, resolvida a questão da irrigação peniana com o Viagra e outros medicamentos similares, a atenção dos especialistas agora recairia sobre questões que indiretamente afetam o desempenho sexual masculino. A nova revolução na área de saúde sexual teria duas bases: o restabelecimento da normalidade hormonal e o estímulo da disposição sexual. A "área hormonal" se mostraria promissora na tentativa de manter a libido por mais tempo, encaminhamento imprescindível, pois a queda dos hormônios no corpo se daria já a partir dos 35 anos de idade. No quadro em destaque intitulado "As armas do homem" afirma-se que a reposição hormonal desde 1999 firmou-se como forma de combater a perda de testosterona e que há médicos que indicam o tratamento a partir de 45 anos, quando alguns homens apresentariam queda no índice desse hormônio. O texto é recheado de declarações de certeza como na frase: "A ação mais positiva da medicina nos anos 90 foi repor esses hormônios na esperança de restaurar a saúde e evitar as doenças associadas à falta daquelas substâncias - entre elas quase todas as disfunções sexuais, como impotência e ausência de desejo." (Carelli, 2002, p. 75). Há ainda a reprodução de um teste com 30 perguntas destinado a avaliar a chamada idade sexual de cada um, cuja autoria original é de Irwin Goldstein, 
urologista da Universidade de Boston, e um dos grandes responsáveis pela disseminação do diagnóstico e tratamento das disfunções sexuais.

No ano seguinte, chama a atenção uma discreta nota, de meia coluna, não assinada, publicada em 23 de julho, encabeçada pela frase "Pura invenção: a andropausa seria apenas uma desculpa para preguiçoso". Nela constatavase que a "teoria" de que o sexo masculino também teria a sua menopausa começava a perder força e de que um número cada vez maior de especialistas afirmaria que "a andropausa simplesmente não existe". Remetia-se então às declarações do professor John McKinlay, pesquisador do New England Research Institute, nos Estados Unidos, que no encontro anual da Sociedade Britânica de Fertilidade disse que os sintomas que costumam acometer os cinquentões nada teriam a ver com a queda na produção de hormônios, sendo resultado de estilo de vida preguiçoso e descuidado. O pesquisador ainda teria dito que a andropausa seria "uma invenção da indústria farmacêutica para vender mais remédio" (Pura invenção, 2003, p. 64).

Mas, se temos essa rara dúvida episódica, o suplemento Veja Especial Homem (2003) editado em outubro do mesmo ano retomaria o rumo anterior. Trata-se de um caderno dedicado a mapear a situação do homem contemporâneo em várias frentes, incluindo comportamento, saúde e sexualidade, e que também parece se propor a ser uma espécie de guia de orientação. Em um dos quadros explicativos de página inteira temos o tema "Pênis+Próstata" e a apresentação de características e problemas dos homens entre os 20 e 70 anos. Descobre-se que aos 30 anos "é o auge da potência sexual" e o ângulo de ereção, devidamente ilustrado em um esquema gráfico, é de 20 graus. Aos 40 esse ângulo reduz-se drasticamente a 5 graus, podendo chegar a menos 1 grau aos 50 e a menos 25 graus aos 70 anos. Parece que os 40 anos representam um momento-chave, tal como é explicado no quadro "O que acontece ao longo dos anos". De acordo com as informações dadas, seria nessa fase que começaria a chamada andropausa e, a partir de então, haveria queda de $1 \%$ ao ano na produção de testosterona, sendo que "apenas" $20 \%$ dos homens precisariam fazer reposição hormonal (Veja Especial Homem, 2003, p. 75). Ao contrário do que sugere o texto, $20 \%$ dos homens com mais de 40 anos representam um contingente bastante numeroso que passaria a ter a obrigação de buscar exames e tratamentos para essa condição de vida ora colocada sob suspeita.

A partir de 2005, já se percebe uma certa consolidação das representações em torno da andropausa e de sua conexão com as questões relativas 
à sexualidade em função do uso dos argumentos dos especialistas, da divulgação de pesquisas quantitativas e do tom triunfante na divulgação de novos remédios. É de se notar inclusive que a busca de outros tratamentos, como o psicoterápico, vai perdendo terreno em face da proposição de novas drogas ou a redescoberta de antigas, como os antidepressivos, para a resolução de problemas sexuais que incluem a dificuldade de ereção, ejaculação precoce e falta de desejo. Isso pode ser ilustrado, mais uma vez, com a matéria de capa da revista Veja de 19 de janeiro de 2005 que, sobre um fundo que destacava um termômetro entre os seios de uma mulher, pontificava "Saúde sexual: a ciência mostra que o bem-estar físico e psicológico depende muito mais da sexualidade do que se pensava" e anunciava o "Teste: descubra seu 'QI sexual". A longa reportagem, assinada por Anna Paula Buchalla, começava lembrando o ditado que diz que "sexo quando é bom, é ótimo e quando é ruim, ainda assim é muito bom". Em seguida apresenta-se o teste de Quociente Sexual (QS) elaborado pela psiquiatra Carmita Abdo, ${ }^{8}$ coordenadora do Projeto Sexualidade (Prosex) do Hospital das Clínicas da USP, que serviria para avaliar a "qualidade da vida sexual". O teste é resultado de entrevistas feitas com 630 homens e 580 mulheres de 18 a 70 anos a partir das quais se pôde chegar a dez quesitos básicos que separariam o "sexo satisfatório" do "sexo desapontador". Segundo Carmita Abdo, deve ajudar os casais a identificar os problemas e o que pode ser melhorado na sua vida sexual. Mais adiante a mesma pesquisadora diz que “o objetivo é que ele seja aplicado em todas as consultas médicas, para orientar o médico sobre os possíveis problemas de seus pacientes, tanto físicos quanto emocionais" (Buchalla, 2005, p. 75). Depois de confirmada a importância do teste, passa-se para o argumento da chancela da Organização Mundial de Saúde (OMS) que inclui o sexo como parâmetro para definir qualidade de vida. E para a constatação de que: "o sexo seguro, freqüente e prazeroso, explicam os médicos, pode proteger o coração, evitar a insônia, aliviar o stress, fortalecer o sistema imunológico, combater a ansiedade, regular o humor, emagrecer e até atrasar um pouco o ritmo do envelhecimento" (Buchalla, 2005, p. 75). Praticamente todos os problemas relativos à saúde e à qualidade de vida do

\footnotetext{
8 Nesse mesmo ano de 2005 Carmita Abdo, mulher e psiquiatra, teria recebido a honra de se tornar membro da Sociedade Brasileira de Urologia, então presidida por Sidney Glina. Esses dois médicos se tornariam personagens centrais no movimento de publicização das chamadas disfunções sexuais e de seus tratamentos no Brasil.
} 
sujeito moderno estão listados nessa frase, indicando a incontornável necessidade de buscar a "melhoria" da vida sexual. E para tanto, são listados uma série de recursos, sempre inovadores e repletos de promessas de satisfação.

$\mathrm{Na}$ sequência, são introduzidos mais dados, sem a referência precisa às fontes, como data ou metodologia de pesquisa, como ilustra a menção de que "oito em cada dez brasileiros (homens e mulheres) vítimas de problemas sexuais declaram que suas aflições afetam o trabalho, o convívio com os filhos, as relações sociais, o lazer", além do convívio com o parceiro (Buchalla, 2005, p. 75). Recorre-se ainda a um estudo simplesmente apresentado como "feito pela FIOCRUZ da Bahia" com 77 mil homens em 24 estados brasileiros que tinham 52 anos em média e que constatou que $66 \%$ dos brasileiros apresentam, em maior ou menor grau, dificuldade de ereção. Além disso, "quanto mais elevada a faixa etária, maiores são a prevalência e a severidade da disfunção" (Buchalla, 2005, p. 76). Na página seguinte, reproduz-se mais uma vez a informação de que a partir dos 40 anos os homens experimentam uma queda na produção de testosterona, definido agora como "o hormônio da libido", sendo que $20 \%$ terão uma queda acima do normal. A isso, sem que a questão da reposição tivesse sido apresentada e discutida, acrescenta-se:

Usualmente essa reposição é feita por injeção, comprimido ou adesivos transdérmicos. Foi lançado recentemente na Europa um novo remédio à base de testosterona, o Nebido, do laboratório alemão Schering AG. Administrado por injeção, ele requer apenas quatro picadas por ano. Os outros medicamentos injetáveis exigem, em média, 22 aplicações anuais. Os comprimidos devem ser tomados duas vezes ao dia. $\mathrm{E}$ os adesivos trocados diariamente. De uso mais simples, o Nebido promete aumentar a adesão do paciente ao tratamento. (Buchalla, 2005, p. 77-78).

Remete-se então ao grande quadro que ocupa duas páginas, intitulado “Ajuda química: os medicamentos que prometem combater as disfunções sexuais masculinas e femininas". No caso dos homens, além dos remédios para ereção e ejaculação precoce, aparecem como já disponíveis para consumo os adesivos, injeções e comprimidos de testosterona ("o gatilho de desejo sexual"), e com previsão de ser lançado no segundo semestre de 2005 o tão bem apresentado Nebido. Como fontes dessas informações, temos Sidney Glina, então presidente da Sociedade Brasileira de Urologia (SBU) e Luiz Otávio Torres, presidente da Sociedade Latino-Americana para o Estudo da Impotência e Sexualidade (Buchalla, 2005, p. 73-74). E para terminar, duas 
informações também trabalhadas com insistência. A primeira é que "graças aos remédios orais aintiimpotência, nos últimos cinco anos quadruplicou o número de brasileiros que procuram ajuda para seus problemas sexuais" (Buchalla, 2005, p. 77). No quadro denominado sugestivamente "Mais liberdade" acrescenta-se que no ano de 2000 apenas $10 \%$ dos brasileiros com disfunção erétil buscavam tratamento, e que em 2005 já seriam 40\%. A segunda informação relevante é a de que as companheiras desses homens teriam sido fundamentais para a procura de ajuda médica, tendo incentivado seus parceiros a tomar essa atitude em 56\% dos casos em tratamento (Buchalla, 2005, p. 78).

No ano seguinte, momento em que a SBU elabora um consenso a respeito da reposição da testosterona para DAEM, a julgar pelo tom da divulgação na imprensa, já teríamos consolidada a categoria de andropausa e a noção de eficácia associada à reposição de testosterona. A mesma jornalista, Ana Paula Buchalla (2006), assina mais uma extensa matéria dessa vez intitulada "O hormônio da juventude: médicos perdem o medo de receitar a reposição de testosterona para homens de meia-idade que apresentam queda acentuada de vigor físico". O artigo começa com um gráfico em duas páginas mostrando a variação nos níveis de testosterona ao longo da vida de um homem, indicando como fontes o Male Aging Study e o New England Research Institute, nos Estados Unidos. Dessa vez somos informados que o pico de produção de testosterona ocorre ao 20 anos e que aos 30 o "hormônio da virilidade" começa a cair em média $1 \%$ ao ano. Aos $40,20 \%$ dos homens já apresentariam sintomas decorrentes da queda hormonal como cansaço, irritabilidade e diminuição da libido. A partir dos $60,30 \%$ e aos 70 anos, $50 \%$ dos homens sofreriam com a queda da testosterona (Buchalla, 2006, p. 116-117). Não se pode deixar de notar que se passa a falar da redução do hormônio e dos seus supostos efeitos para idades cada vez menores. Se antes o marco de redução de $1 \%$ ao ano era a partir dos 40, agora foi adiantado para os 30 anos.

A matéria logo informa que a andropausa afetaria $20 \%$ dos homens que sofrem com irritabilidade, alterações do sono, dores, cansaço físico, desânimo generalizado, diminuição de desejo sexual e perda de potência. E acrescenta que esses sintomas "foram constatados por um estudo patrocinado pelo laboratório Schering do Brasil e coordenado pela psiquiatra Carmita Abdo, do Projeto Sexualidade (Prosex), do Hospital das Clínicas, de São Paulo". Ao que se adiciona a frase "como se vê, o homem é mesmo a sua testosterona" (Buchalla, 2006, p. 117). Segue dizendo que, se até pouco tempo atrás não 
havia consenso sobre a reposição hormonal, nos últimos cinco anos, mais de uma centena de estudos científicos mostrara a sua validade. Além disso, nenhuma pesquisa teria conseguido "provar com rigor" a associação entre reposição de testosterona e câncer de próstata e que, aos poucos, a ciência também começava a "derrubar outro mito", de que a reposição seria fator de risco para doenças cardiovasculares. Entre outros especialistas temos mais uma vez Carmita Abdo dizendo que "tudo indica que o hormônio extra propicia que se viva mais e melhor" (Buchalla, 2006, p. 118).

De fator de risco, a testosterona é agora transformada em fator de proteção contra doenças e incremento fundamental para quem busca longevidade e vida sexual ativa. O texto segue dizendo que "a testosterona está tão em evidência que, só no ano passado, foram publicados cerca de sessenta estudos sobre a sua reposição" (Buchalla, 2006, p. 119) e que o mais impactante deles mostrava que homens com deficiência de testosterona tinham mais chances de morrer e que $88 \%$ tinham risco maior de desenvolver doenças crônicas graves. A isso segue a declaração do urologista Sidney Glina, do Instituto H. Ellis, de São Paulo: "Diante das evidências, nós, médicos, perdemos o medo de receitar testosterona" (Buchalla, 2006, p. 119).

A construção da reposição da testosterona como "fato e evidência" passa ainda pela utilização de cifras referentes ao consumo, evidenciando a criação de um novo e produtivo mercado. A revista menciona que, segundo a consultoria IMS Health, as farmácias americanas receberam 2,4 milhões de prescrições em 2005, o que representava o dobro em relação a dois anos atrás. Cita ainda, sem dar a referência, um artigo no The New England Journal of Medicine que constatava um aumento de 500\% nas vendas de suplementos de testosterona desde 1993. E finaliza: "De acordo com as projeções da indústria farmacêutica, dentro de cinco anos esse mercado ultrapassará a casa do bilhão de dólares em faturamento." (Buchalla, 2006, p. 119). Certamente temos aí explicitado um indício importante do interesse dos laboratórios farmacêuticos na construção da medicalização da andropausa.

Outra "evidência" acionada no texto é que em países desenvolvidos, o exame de testosterona já teria se tornado um procedimento de rotina, confirmando a necessidade de ser mais incentivado aqui no Brasil. O texto termina propondo que a "absolvição da testosterona" pode estimular os homens a cuidarem mais da saúde, já que menos de 60\% dos homens com mais de 40 anos visitariam um médico regularmente e que, quando o fazem, são levados 
por suas companheiras. Reforça-se assim a ideia, que seria mais recorrente nos anos seguintes, da preocupação dos homens com a sexualidade, principal referência de interesse para usar a testosterona, e sua entrada mais consistente no universo dos cuidados e do consumo dos exames e tratamentos de saúde. E mais uma vez, as mulheres aparecem como aliadas estratégicas.

Além de depoimentos, com fotos, de dois empresários, de 44 e 68 anos, que atestam as benesses da reposição hormonal, temos ainda dois quadros na mesma matéria. Um deles cita as indicações, advertências e contraindicações do uso da testosterona sintética e explica suas formas de administração. São referidos adesivos transdérmicos (30\% dos pacientes relatam irritação local), comprimidos (com o inconveniente de serem ingeridos duas vezes ao dia e com risco de alterações metabólicas acentuadas), implantes subcutâneos (contraindicados para paciente idosos em função dos riscos de infecção), géis (não são relatados problemas associados). Mas, o que aparece em primeiro lugar na lista são as injeções intramusculares, apresentadas como o método mais utilizado de reposição hormonal. E se as mais antigas tinham o inconveniente de requerem em média 22 aplicações anuais, "recentemente foi lançada no Brasil uma nova injeção de testosterona, o Nebido, que requer apenas quatro picadas por ano. A outra vantagem é que ela evita alterações drásticas nas taxas hormonais." (Buchalla, 2006, p. 120). Além do Nebido ser destacado apenas pelas suas vantagens, é preciso dar atenção ao fato de que é o único medicamento cujo nome comercial é citado na reportagem. ${ }^{9}$

$\mathrm{O}$ outro quadro em destaque é um teste que aparece com o título "A quantas anda o seu hormônio?" Embora não seja citada a fonte, trata-se na verdade da reprodução da conhecida escala sobre o envelhecimento masculino (Aging Male's Symptoms Scale - AMS). O questionário é apresentado como instrumento que mede o grau de envelhecimento masculino a partir dos 40 anos de idade, com base em uma análise dos sintomas de queda na produção da testosterona. A novidade é que aqui, além das tradicionais 17 perguntas do teste, segue-se uma avaliação referente ao número de pontos obtidos por

\footnotetext{
9 Esse tipo de matéria e a menção explícita ao Nebido se repetem em outras revistas, como a matéria publicada na Isto é (Côrtes; Rodrigues; Freitas Jr., 2006), com o título "As fragilidades do homem: descobertas científicas estão mudando o entendimento do que ocorre no corpo e na mente dos indivíduos com mais de 40 anos". Chamava a atenção para tratamentos da andropausa, responsável por repercussões importantes na vida do homem, como redução da força e energia, prejuízo à função cognitiva e menos desejo e potência sexual. Dentre as alternativas pesquisadas comentava-se que a "opção clássica" era a reposição de testosterona e que a novidade era o lançamento no Brasil do Nebido.
}

Horizontes Antropológicos, Porto Alegre, ano 17, n. 35, p. 161-196, jan./jun. 2011 
cada indivíduo. Quem teve como resultado entre 17 e 26 pontos fica sabendo que pertence à "categoria de homens que ainda não sentiram os efeitos da baixa produção de testosterona". Aquele com 27 a 36 pontos descobre que "os primeiros sintomas da queda de testosterona começam a aparecer" e que deve ficar "atento aos sinais que seu organismo emite". Entre 37 e 49 pontos percebe que os sintomas "são ainda moderados, mas talvez já seja o caso de procurar orientação de um especialista" que poderá indicar ou não a reposição hormonal. Já para quem obteve um escore de 50 pontos ou mais "a qualidade de vida está seriamente comprometida pela baixa na produção do hormônio testosterona". Além disso, "o resultado do seu teste sugere que você deve procurar um médico para que ele avalie qual a melhor terapia de reposição hormonal para o seu caso" (Buchalla, 2006, p. 119). Em primeiro lugar, é preciso comentar que muito facilmente qualquer pessoa assinalaria positivamente, pelo menos nos graus "pouco" ou "moderado" quesitos tão genéricos como "redução da sensação de bem-estar geral", "alterações no sono", "sensação de cansaço" ou "irritabilidade". Quem marcou sete vezes a opção "nenhum" e dez vezes "pouco" já entra na categoria de quem está sentindo os primeiros sintomas. E assim sucessivamente, com muita facilidade, os homens podem chegar às categorias subsequentes e descobrir que estão em plena andropausa e que têm a obrigação de procurar orientação e tratamento. Nota-se ainda que no caso daqueles com mais de 50 pontos, para os quais bastava ter assinalado o grau "moderado" em todos os quesitos, a indicação de reposição é taxativa cabendo ao médico apenas decidir qual a melhor terapia.

No ano seguinte com facilidade se encontrava a reprodução desse questionário em revistas de grande circulação, como na Época na edição de 26 de março de 2007. ${ }^{10}$ Trata-se na verdade de um anúncio da Schering, que traz o logotipo do laboratório no alto da página, à esquerda. À direita, temos uma foto de um homem de não mais de 50 anos e no centro, em destaque, a sigla DAEM acompanhada da chamada "Homem com mais de 40 anos: se a falta de ânimo e de desejo sexual já fazem parte de sua vida, isto lhe interessa". Abaixo temos uma explicação:

DAEM significa Distúrbio Androgênico do Envelhecimento Masculino (também conhecido como andropausa) e está diretamente relacionado ao decréscimo

${ }^{10}$ A andropausa passa a ganhar destaque até mesmo em revistas femininas, como aparece na matéria "Andropausa: homens à beira de um ataque de nervos", publicada na Claudia (Nabuco, 2007). 
da produção de Testosterona após os 40 anos de idade. Entre os sintomas estão a perda da libido (desejo sexual), diminuição da massa muscular, perda da energia, depressão, disfunção erétil e pode haver aumento do risco de doenças cardiovasculares. Se você tem mais de 40 anos e quer saber se tem sintomas relacionados ao DAEM, responda à escala abaixo e leve-a à consulta médica. (Época, 26 mar. 2007, p. 11).

Dessa vez é citada a fonte da Aging Male's Syntoms Scale (AMS) e feita uma observação de que a escala é uma importante ferramenta para auxiliar o médico a avaliar a saúde e a qualidade de vida do homem maduro, além de ser mundialmente utilizada e padronizada segundo as normas psicométricas. Por fim há ainda a referência a dois sites e o telefone do serviço de atendimento ao consumidor da Schering. Exatamente essa mesma página era distribuída nos congressos da área de sexualidade e urologia naquele ano, como o XI Congresso Brasileiro de Sexualidade Humana, realizado em outubro de 2007, em Recife. Nos estandes montados pela Schering distribuíam-se fartamente blocos inteiros com a reprodução da escala. Ocorreram inclusive congressos especificamente destinados ao tema, como o intitulado "Sexualidade e DAEM", realizado pela Associação Brasileira para o Estudo da Inadequação Sexual (ABEIS) em 6 de junho de 2007, em Campinas (SP).

Mas é no $31^{\circ}$ Congresso Brasileiro de Urologia, realizado na gestão de Sidney Glina como presidente da SBU, que o tema seria tratado com ainda mais entusiasmo. No evento realizado entre 27 de setembro e $1^{\circ}$ de outubro de 2007 em Salvador e contando com a participação de mais de 5500 congressistas, a Bayer Schering Pharma (laboratório criado a partir da aquisição da Schering pela Bayer) anuncia o lançamento de uma área específica de saúde masculina centrada na promoção do Nebido, para tratamento do DAEM, e do Levitra, destinado ao tratamento da disfunção erétil. Na coletiva de imprensa desse lançamento o destaque era a apresentação dos dados da nova pesquisa coordenada por Carmita Abdo e realizada com financiamento da Bayer Schering Pharma. Tratava-se do Estudo Populacional do Envelhecimento (EPE), pesquisa feita com 10.161 participantes em 18 capitais brasileiras entre fevereiro e junho de $2006 .{ }^{11}$

11 Os resultados completos seriam publicados em 2009 no Estudo populacional do envelhecimento no Brasil (Abdo, 2009). 
No artigo destinado a apresentar os resultados iniciais da pesquisa no que se refere aos homens, informa-se que se trata de uma investigação com questionários autorresponsivos preenchidos por voluntários com 40 anos ou mais, transeuntes de ruas, praças, praias, parques e shopping centers, com questões de saúde geral e sexual, hábitos de vida e perguntas da escala AMS. De acordo com os resultados, os parâmetros obtidos indicam que 13,3\% dos pesquisados teriam "sintomas sugestivos de DAEM" (Abdo; Afif-Abdo, 2007, p. 381). Além disso, o artigo repete algumas vezes que os homens "com AMS moderado/grave apresentaram duas vezes mais DE [disfunção erétil] (em geral) e três vezes mais DE completa do que aqueles com AMS de índices menores" (Abdo; Afif-Abdo, 2007, p. 382), reforçando a conexão entre DAEM e disfunções sexuais. Outra informação repetida é que "chama a atenção que a grande maioria desses homens não dosou a testosterona nos últimos 12 meses e que, dentre os que dosaram, significativo contingente (o equivalente a $9,0 \%$ do total de homens) teria níveis baixos de testosterona, se a proporção de $1,8 \%$ em cada $20,0 \%$ se mantivesse nos demais $80,0 \%$ que não fizeram essa dosagem" (Abdo; Afif-Abdo, 2007, p. 382). O cálculo é no mínimo curioso, mas serve para corroborar a ideia de que os homens precisariam fazer mais exames e para sustentar a orientação no final do trabalho de que é necessário fazer campanhas e intervir mais precocemente na prevenção de doenças nesses indivíduos.

\section{Andropausa: popularização e legitimação oficial}

As peças do cenário descrito acima se encontram bem amarradas em mais um episódio de divulgação da andropausa ou DAEM, veiculada inicialmente em 28 de agosto de 2007. Trata-se do programa de televisão Saúde Brasil, com duração de 30 minutos, sobre DAEM, produzido pelo Projeto Saúde Brasil e veiculado em emissoras públicas como TVE Brasil e TV Cultura. ${ }^{12}$

\footnotetext{
12 De acordo com as informações da TV Cultura: "Saúde Brasil é uma série de documentários educativos voltados para a área de saúde em especial à prevenção. Além de orientação básica, o programa desmistifica preconceitos e mitos que envolvem várias doenças. Produzido pela Aguilla Produção e Comunicação, o programa mostra o que é a doença, sintomas, causas, fatores de risco, tratamento, cuidados e orientações." Conta com apoio do Programa Nacional DST/AIDS, Governo do Estado e Prefeitura de São Paulo. Ver o site do programa em http://www.tvcultura.com.br/saudebrasil.
} 
Apresentado pela jornalista Lina Menezes, que também divide a direção com Gilney Rodrigues, tem como estrutura básica a definição do problema, seus sintomas e riscos e as possíveis soluções, pautadas por declarações de especialistas e entrevistas com "pessoas comuns". A apresentadora inicia dizendo que vai se falar de um tema que tem despertado muito interesse. Trata-se da relação do hormônio testosterona com a saúde do homem a partir dos 40 anos, o que ocorre com o organismo masculino e os cuidados que o homem também deve ter para manter sua saúde e qualidade de vida. Parte-se para uma comparação com a menopausa, por meio das explicações da endocrinologista Ruth Clapauch e do urologista Geraldo Eduardo Faria, que afirma que no caso do homem a queda dos hormônios é lenta e gradativa, fazendo com que os sintomas não sejam identificados com muita clareza. Além disso, acrescenta que "hoje nós sabemos que é muito importante que, ocorrendo a diminuição dos hormônios masculinos, o homem necessita ser tratado para poder recuperar sua qualidade de vida".

Na sequência temos a participação de Sidney Glina dizendo que "alguns homens vão ter uma diminuição importante a partir de 50 anos, assim estimase entre $10 \%$ e $15 \%$ dos homens, e isso vai ser uma doença que hoje tem o nome próprio que é o de, algumas pessoas chamam de andropausa, que não é o nome que eu gosto, mas a gente chama de deficiência androgênica do envelhecimento". Para Ruth Caplauch, estima-se que 20\% dos homens entre 60 e 69 anos tenham andropausa e esse percentual vai subindo vagarosamente quando se aumenta a idade. Entre 70 e 79 anos o percentual seria de $30 \%$ e acima dos 80 anos, 50\%. De acordo com Glina, DAEM, ou andropausa, "é uma doença, ela precisa ser tratada. As pessoas que têm sintomas parecidos devem procurar um médico pra fazer o tratamento adequado, porque a testosterona é um hormônio importante." Sendo um "hormônio extremamente importante" produzido pelo homem, é responsável por várias ações do organismo humano, como diferenciação sexual, desejo sexual, ereção, manutenção da massa muscular e da memória. Essa tese é reforçada pela psiquiatra Carmita Abdo ao afirmar que "a testosterona é um hormônio sexual por excelência", é o que "faz brotar o desejo sexual" e, quando está diminuído, "logicamente, esse desejo começa a ficar prejudicado". Acrescenta que "a tal perda da libido ou a diminuição da libido, que tanto é hoje comentada, se deve tanto em homens como em mulheres à diminuição dos níveis sanguíneos de testosterona". E que, além da "competência erétil", a queda nos níveis de testosterona pode ocasionar 
prejuízo na capacidade reprodutiva. $\mathrm{O}$ narrador do programa informa que as dificuldades na esfera sexual por parte do homem com DAEM "prejudicam as relações conjugais", sendo que "o casal não faz ideia de que o motivo é considerado uma enfermidade e pode e deve ser tratada".

Em seguida Lina Menezes abre o tópico sobre como a diminuição da testosterona pode afetar vários órgãos ou funções do organismo masculino, o que é ilustrado pelo comentário de Geraldo Eduardo Faria: "Você quando olha o indivíduo homem que está com uma deficiência hormonal é muito característico aquela figura do indivíduo que tem o braço muito fininho, a musculatura já está atrofiada." Segundo o médico, nessa situação, o homem vai perdendo a capacidade de transformar a proteína ingerida na sua alimentação em massa muscular. Ruth Caplauch diz então que a testosterona "age a nível do sistema nervoso também, fazendo um estado de humor mais adequado. Enfim, age na próstata, age nos ossos, age na pele, age nos glóbulos vermelhos. Eu diria que são ações no corpo inteiro." A isso a apresentadora acrescenta que a testosterona tem uma ação direta ainda sobre o cérebro, o que é novamente confirmado por Faria ao dizer, a respeito da queda de testosterona, que o indivíduo tem uma diminuição da sua capacidade de concentração, uma queda na sua intelectualidade, dificuldade para entender as coisas e para o aprendizado, e sonolência, manifestações que seriam características da atividade cerebral. Fala-se ainda de "vários impactos negativos, prejudicando sua qualidade de vida" e de depressão, cansaço, sonolência, apatia, irritabilidade, de gordura abdominal, aumento de risco cardiovascular e osteoporose, além de associação com diabetes e síndrome metabólica.

O programa prossegue tratando da dificuldade de reconhecer os sintomas, o que conduz à imagem de uma espécie de ameaça silenciosa e à necessidade de procurar um especialista que saiba reconhecê-los e proporcionar o tratamento correto. Tanto Glina quanto Faria aparecem fazendo ponderações a respeito da importância de se considerar a individualidade de cada caso. Mas isso logo é substituído pela ênfase nos exames de dosagem de testosterona e por imagens de laboratório. E passa-se, então, para a descrição dos tratamentos, mediada por uma rápida fala de Caplauch sobre o balanço entre riscos e benefícios. Geraldo Eduardo Faria explica que no Brasil a grande maioria dos tratamentos são feitos através de injeções de testosterona ministradas a cada doze ou quinze dias, mas que "mais recentemente, nós tivemos agora lançado no mercado brasileiro uma testosterona injetável de ação prolongada, é muito 
mais cômoda porque a pessoa vai tomar uma injeção a cada três meses". Falase também no uso de gel e comprimidos de administração oral, mas em ambos os casos são associados problemas na absorção.

Já encaminhando para a o final do programa, temos o reforço da importância da testosterona para o casal e a função da mulher no auxílio ao diagnóstico e tratamento. Segundo Faria, é importante o papel da mulher também na identificação do problema, quando seu companheiro começa a ter manifestações clínicas que possam sugerir que ele poderia ter um quadro de andropausa: "É importante que essa parceira, essa esposa, essa companheira incentive o seu companheiro a procurar um médico pra ver se realmente ele está num quadro de andropausa e ele poderia aí se beneficiar do tratamento." Além disso, recorre-se ao tema do possível preconceito relativo ao tratamento. Dessa vez aparece primeiramente o depoimento de um senhor de 73 anos dizendo: "Sem nenhuma dúvida, eu não tenho nenhum preconceito contra isso, pelo contrário, eu acho que tudo que puder melhorar a sua performance na vida, seja física, seja intelectual, seja sentimental, porque essas coisas estão todas relacionadas, não é? Eu acho que convém fazer." Essa opinião é avalizada pela psiquiatra Carmita Abdo ao declarar que "não se deve ter preconceito em relação à chamada andropausa, a deficiência androgênica do envelhecimento masculino porque ela tem cura, ela tem resolução." Ao que acrescenta: "a andropausa, ou deficiência androgênica do envelhecimento masculino, como ela deve ser chamada, tem solução e cabe ao homem buscá-la." Introduz-se, dessa forma, o tema relativo ao dever de se informar e cuidar da saúde que deveria caracterizar o cidadão contemporâneo. Esse ponto é sintetizado na frase do narrador, que determina: "Cuidar da saúde deve ser um compromisso por parte de cada um. Especialmente nos dias de hoje em que o aumento na expectativa de vida é uma realidade." Para fechar, logo após a indicação de algumas instituições de referência, encabeçadas pela SBU, a apresentadora então conclui:

Bom, se você é homem, tem mais de 40 anos, fique atento aos sintomas. Pode ser distúrbio androgênico do envelhecimento masculino, também conhecido como andropausa. E, como vimos, a deficiência de testosterona, o principal hormônio sexual masculino, que pode ocorrer nessa fase, pode ser tratada com terapia de reposição, o que ajuda o homem a recuperar sua qualidade de vida e viver mais tempo, mais feliz. 
Pode-se concluir que o programa cumpre seu objetivo de informar sobre o DAEM ou andropausa, problema que tem "despertado muito interesse" fazendo as exigidas ressalvas no que se refere à necessária consulta ao médico e à importância da avaliação individual. Porém o que se destaca é o caráter de certeza na forma em que é apresentado o DAEM como uma "doença" ou "enfermidade" que inclusive "tem cura", a tão propagandeada reposição hormonal via as recém-lançadas injeções de testosterona de longa duração. Nota-se ainda, no que se refere às imagens utilizadas, que além dos especialistas e dos transeuntes entrevistados, o que mais aparece na tela, em 12 ocasiões, são cenas de médicos ou médicas prescrevendo, frequentemente com ângulos fechados nas mãos empunhando canetas e nos próprios receituários. Certamente, essas imagens remetem para o enquadramento mais geral do programa, que parece pautado pela medicalização.

É importante relatar que a SBU aparece com destaque nos agradecimentos mostrados nos créditos do programa, o que pode ser visto como mais um indício da consolidação dessa entidade como principal fonte legítima de informações sobre a andropausa. No site da sociedade, já era comum a presença desse tema com frequência. No início de 2008 a imagem de maior destaque na página inicial, na parte central e superior da tela era o logotipo "DAEM", tal como aparecia exatamente nas propagandas e na escala divulgada pela Bayer Schering Pharma.

Se as grandes matérias em revistas como a Veja e a Isto é anunciavam a andropausa para um certo público de capital financeiro e educacional "superior", o que é ilustrado por exemplo pelo tipo de linguagem escrita e gráfica e pelas imagens de empresários que fazem uso dos tratamentos de reposição, nota-se um progressivo surgimento do tema em novos cenários e com novos enquadramentos. ${ }^{13} \mathrm{O}$ programa de televisão descrito acima apresenta essa característica tanto no uso de imagens de pessoas de camadas mais populares quanto na linguagem repetitiva e simplificadora. Isso parece se coadunar com as estratégias que passam a ser encampadas pela SBU nos últimos anos em torno de incentivar a atenção à saúde masculina. Em 2009, por exemplo, realizou, em parceria com a Bayer Schering Pharma, campanhas exclusivamente

${ }^{13}$ Ver, por exemplo, a matéria "Repor testosterona é opção após os 60 anos", no jornal $O$ Globo de 10/02/2008, que salientava a necessidade da reposição para $10 \%$ a $13,3 \%$ dos homens a partir dos 40 anos que apresentavam sintomas de DAEM (Marinho, 2008). 
dedicadas ao esclarecimento sobre DAEM em Goiânia, Porto Alegre e Natal, em praças públicas e estacionamento de supermercado. O objetivo, de acordo com José Carlos de Almeida, então presidente da SBU, era explicar à população "diagnósticos, sintomas e tratamentos para o problema, que atinge de $20 \%$ a 30\% dos homens a partir dos 40 anos" sem o seu conhecimento, caracterizando o DAEM como uma "doença silenciosa". Nesse mesmo ano, a Rádio SBU, dispositivo de divulgação de informações acessível via o site da SBU, disponibilizava palestras sobre os temas em questão, como a intitulada "Males do envelhecimento", que descrevia os problemas associados à diminuição progressiva das taxas de testosterona, "o hormônio masculino", mais acentuada em 20\% dos homens, que deveriam buscar os tratamentos de reposição.

Paralelamente, também em 2009, continuava a discussão e promoção do DAEM como um tópico de destaque nos congressos médicos. No $32^{\circ}$ Congresso da SBU, realizado em Goiânia e descrito como o maior evento do setor na América Latina, foram apresentadas as novas diretrizes para diagnóstico e tratamento do DAEM, com a proposta de unificar os procedimentos no Brasil. No $10^{\circ}$ Congresso da Sociedade Latino-Americana de Medicina Sexual (SLAMS), ocorrido em Florianópolis, o tema também teve destaque e foi distribuído um livreto intitulado A saúde sexual como portal da saúde do homem, editado pela Bayer Schering Pharma, que enfatizava os benefícios do Nebido com o slogan "Em DAEM, tenha em vista a primeira e única injeção trimestral de testosterona" (A saúde sexual..., 2008).

Em 2010, percebe-se um reforço na estratégia de realizar campanhas de divulgação de maior vulto, como é o caso da implementação do chamado Movimento pela Saúde Masculina. Trata-se de uma iniciativa da SBU com o objetivo de conscientizar a população para a necessidade da prevenção e do tratamento de doenças do homem como a disfunção erétil, a andropausa e as doenças da próstata. A Unidade Móvel do Movimento (uma carreta equipada com consultórios e equipe com três urologistas e outros profissionais de saúde), patrocinada pelo laboratório Lilly, percorria as grandes capitais do país disponibilizando orientação médica gratuita.

Essa estratégia de campanhas diretas, oferecendo à população dos grandes centros a possibilidade de acesso imediato aos urologistas, precisa também ser contextualizada dentro do movimento mais geral de atuação pública da SBU, inclusive como agente importante no processo de criação de uma Política Nacional de Atenção Integral à Saúde do Homem, lançada 
oficialmente em agosto de 2009. Como mostraram Carrara, Russo e Faro (2009), desde pelo menos 2004 a SBU vinha exercendo pressão em setores do governo, parlamentares, conselhos de saúde e outras sociedades médicas no sentido da elaboração de uma política nessa direção. Em 2008 a iniciativa se concretizou na assinatura de um acordo de cooperação técnica entre a SBU e o Ministério da Saúde, com o objetivo de promover a assistência ao homem no sistema público de saúde, via a orientação dos médicos e a promoção de campanhas de esclarecimento, sendo a primeira delas dedicada à disfunção erétil e realizada ainda entre julho e setembro de 2008 (Carrara; Russo; Faro, 2009, p. 663-665).

Como último dado referente à trajetória de criação e legitimação do DAEM no cenário brasileiro, pode-se citar a presença dessa categoria e a forma como é definida no Portal da Saúde (sessão saúde do homem), site oficial do Ministério da Saúde. Nele o DAEM é apresentado como a queda gradual do hormônio sexual masculino (testosterona), ao que se segue a seguinte explicação:

O motivo para a decadência é que os níveis de testosterona, o principal hormônio masculino, começam a cair até $1 \%$ a cada ano a partir dos 30 anos de idade. A redução é gradual, mas permanente. Então por volta dos 50 anos, cerca de $10 \%$ dos homens apresentam níveis baixos de testosterona. Aos 70 anos, mais da metade sofre com deficiência do hormônio. Aos 80 anos, a maioria dos homens tem níveis de testosterona e comportamentos semelhantes ao de meninos antes da puberdade. (Ministério da Saúde, [s.d.]).

Não se pode deixar de notar que o dado chancelado pelo Ministério, portanto, é da queda de $1 \%$ ao ano a partir dos 30 anos e de que a redução na taxa de testosterona está associada a "comportamentos" próximos ao de meninos antes da puberdade. Além disso, são descritos sintomas como fadiga intensa, níveis de depressão, irritabilidade, distúrbios da ansiedade, alterações inexplicáveis de humor, sensibilidade, insônia, diminuição da libido, fraqueza, perda de massa muscular e dificuldade para obter ereções. E no item diagnóstico propõe-se que quando os sintomas são reconhecidos, deve-se realizar a dosagem de testosterona livre, sendo que "se os níveis estiverem abaixo de 200 nanogramas/dl e a pessoa não possuir fatores de risco significativos, a terapia de reposição de testosterona (ou trt) pode ser iniciada", desde que, 
evidentemente, sob supervisão médica (Ministério da Saúde, [s.d.]). Como é possível perceber, não há mais uma discussão de vulto sobre a existência ou não do DAEM ou questionamento sobre a validade da terapia de reposição hormonal, mas apenas as advertências sobre a necessidade de acompanhamento profissional e a adequação do diagnóstico e tratamento a cada paciente, comuns em todos os informativos sobre qualquer "doença".

\section{Andropausa: uma trajetória consolidada}

A descrição apresentada sobre a criação da andropausa como uma nova entidade que começa a fazer parte do cenário de atenção à saúde masculina, que recentemente se instaura no Brasil, permite levar mais a fundo a discussão sobre o processo de construção de novas doenças. Na verdade, pode-se até mesmo propor um esquema analítico a partir do qual é possível reconhecer um contexto, um processo, os meios mais importantes, os personagens principais, e os produtos alcançados. Evidentemente, não está se afirmando a inexistência da andropausa ou de características percebidas pelos sujeitos em questão como relacionadas à dimensão física, como as taxas hormonais medidas em laboratório ou as próprias sensações descritas pelos homens. Ao mesmo tempo, também não se pretende questionar a importância de que a população masculina tenha direito a uma atenção maior à saúde. Mas o que se tentou mostrar foram as articulações de interesses variados que estão associadas à produção da andropausa como uma nova categoria de diagnóstico e tratamento.

Nesse sentido, o contexto mencionado se refere a uma conjunção de fatores entre os quais se destaca um processo mais geral de medicalização da vida relacionada à preeminência de uma associação bastante persistente entre saúde, juventude, beleza e atividade sexual que se traduz em uma série de prerrogativas e cuidados corporais que têm se desenvolvido de maneira mais intensa nas últimas décadas. A ampliação da cobertura dos diagnósticos sobre vários momentos e condições da vida, ao lado dos progressos tecnológicos que viabilizam um escrutínio maior do corpo, além de inovadoras possibilidades terapêuticas, certamente têm sido fatores importantes. Mas, no caso da andropausa, deve-se acrescentar outros aspectos que incidem exatamente sobre a conexão entre sexualidade e envelhecimento. Em primeiro lugar, trata-se da inspiração no sucesso da transformação dos problemas da ereção em uma categoria médica específica, a disfunção erétil, surgida concomitantemente à 
"descoberta" das drogas que possibilitam seu tratamento. Já havia portanto um caminho aberto para que os homens atentassem mais para a sexualidade, traduzida e reduzida aqui na função erétil e um incentivo promovido publicamente através de diversas formas de divulgação para que procurassem acessar aos recursos disponíveis (Rohden, 2009). Um novo clima cultural e uma potente infraestrutura médico-farmacêutica estavam disponíveis e puderam tornar possível a criação da andropausa (Marshall, 2007).

Destaca-se também a configuração de um novo modelo de representação corporal centrado na importância dos hormônios para a definição das características individuais, sobretudo aquelas relacionadas à diferenciação sexual e à sexualidade (Oudshoorn, 1994; Rohden, 2008). Acrescenta-se a isso o sucesso na medicalização da menopausa que, apesar dos riscos associados, é majoritariamente descrita, nos discursos biomédicos e leigos, como um período de perdas que precisam ser coibidas ou retardadas via os tratamentos de reposição hormonal (Senna, 2009). E por fim, tem destaque o desenvolvimento de uma agenda pública de reivindicação por maior atenção à saúde masculina, promovida pela articulação entre vários agentes entre os quais se destacam os urologistas, expressa até mesmo em novas políticas governamentais. Como enfatizam Carrara, Russo e Faro (2009), esse movimento acabou se fundamentando em uma perspectiva de vulnerabilização dos homens que, longe de aparecerem como sujeitos demandantes de direitos, surgem como vítimas de sua própria natureza e da falta de cuidados.

No que se refere ao processo e aos meios, pode-se destacar o surgimento dos primeiros artigos científicos sobre a andropausa e a criação de uma escala de medição e portanto de características mensuráveis e sintomas correlacionados. É a partir da escala AMS que se produzem os primeiros dados referentes ao novo diagnóstico e que também se promove a sua divulgação. Trata-se assim de um instrumento fundamental nos planos da pesquisa e da discussão acadêmica, da produção de números que serão repetidos insistentemente como padrões de referência, da própria divulgação enquanto uma peça explicativa do que vem a ser a nova "doença" ou "distúrbio" e no âmbito do autodiagnóstico, como ferramenta mediadora entre o possível paciente e a procura por atendimento médico e tratamento. Em se tratando dos clínicos, é a escala que facilita e viabiliza um diagnóstico que é novo e pouco conhecido, permitindo e incitando a prescrição de um tipo específico de medicamento. No caso do material analisado, é preciso mencionar mais uma vez que o único nome de remédio com marca registrada que aparece é o Nebido, da Bayer 
Schering Farma, lançado no Brasil no mesmo período em que a andropausa começa a despontar como tema de interesse. Nesse aspecto, vale ainda um comentário específico sobre a própria ideia de criação de interesses. Várias reportagens, panfletos, entrevistas mencionam a ideia de que a andropausa tem se tornado um assunto de grande interesse sem, evidentemente, reconhecer sua própria função como promotores desse processo. Assim, por meio de um discurso circular, ajuda-se a fortalecer a ideia de que haveria uma demanda por conhecimento e tratamento do problema que está sendo construído de maneira concomitante.

Nesse sentido, é importante frisar o papel da mídia, que ocupa aqui um lugar não apenas do que poderia se chamar simplesmente divulgação científica. Pois muito além de um processo de transmissão de informação ou tradução das intrincadas e complexas descobertas da ciência para o grande público, o que se faz é ajudar efetivamente a construir novas realidades sociais. É nas páginas das revistas e jornais ou nas cenas dos programas de televisão que os números ganham cores e imagens permitindo o autoenquadramento do público. É lá que se veem fotos ou depoimentos de personagens "comuns" contando suas experiências de sofrimentos e seus momentos de redenção e sucesso com os tratamentos, o que pode sugerir uma identificação e uma aproximação com aquele tipo de trajetória. E é também nesses espaços que se atesta a validade das proposições, sejam elas de diagnóstico ou tratamento, via a autoridade científica e médica.

Nesse ponto já se pode falar sobre os personagens de destaque nesse processo. Especialmente no caso dos discursos sobre a andropausa que foram compilados, pode se destacar a presença do urologista Sidney Glina e da psiquiatra Carmita Abdo, dois médicos vinculados a importantes instituições de ensino, pesquisa e tratamento que aparecem insistentemente como especialistas do tema. É interessante notar que, no caso da promoção de novos diagnósticos, o papel dos experts combina necessariamente a referência à legitimidade científica e acadêmica ao capital ético associado tradicionalmente à profissão médica (Fishman, 2004). Sua credibilidade é atestada não apenas pela capacidade de produção e manipulação de dados e informações, referências internacionais, percentuais, mas também pelo fato de ser um cuidador que, por definição, deveria estar comprometido com a atenção à saúde e ao bem-estar de seus possíveis pacientes.

No que se refere aos resultados desse processo pode-se sugerir que a trajetória de construção da andropausa como uma categoria pública e enquanto 
uma nova entidade de diagnóstico e tratamento teve pleno êxito. Sua inclusão no site do Ministério da Saúde e a forma como é definida nos dão indícios do calibre de sua legitimidade atualmente. Além disso, os termos usados para defini-la como distúrbio, doença, enfermidade, doença silenciosa permitem assumir que não haveria mais dúvidas sobre a sua natureza ou desconfiança sobre a sua qualidade de patologia. E certamente a menção a idades cada vez mais baixas como pontos de início da diminuição da testosterona e aparecimento da andropausa corroboram a imagem de sua prevalência e severidade.

Caberia, portanto, aos homens bem-informados procurar recursos para o diagnóstico e, se for o caso, tratamento precoce, buscando assim suprimir ou amenizar as consequências da doença. Se considerarmos que no contexto contemporâneo da nossa sociedade há um aumento generalizado da responsabilização do sujeito pelos riscos associados aos problemas de saúde e o incentivo ao autocuidado, a andropausa passa a ser mais uma das ameaças a serem vigiadas. De um lado, essa abordagem se coaduna com o discurso do risco. De outro, associa-se de maneira ímpar com a valorização do consumo enquanto atributo correspondente à imagem do sujeito moderno. É tarefa desse sujeito procurar ter acesso ao conhecimento e aos recursos que lhe garantiriam não só a manutenção de sua saúde mas, mais do que isso, um aprimoramento das suas capacidades e um bom gerenciamento de suas funções. Está em jogo aqui o advento da ideia de que é preciso buscar sempre uma melhoria no desempenho corporal, para a qual existiriam uma infinidade de possibilidades disponíveis. Esse argumento leva em conta de maneira particular as novas modalidades de percepção a respeito das fases da vida e de funções "normais" (no sentido de não necessariamente patológicas), como a sexualidade e a reprodução. No caso do envelhecimento, é de se notar a transformação ocorrida no último século entre uma concepção que admitia a passagem da idade e correlatas alterações nas capacidades corporais, para uma outra, que privilegia o império da juventude e procura, por meio das mais diferentes intervenções, adiar ao máximo ou negar a chegada do envelhecimento. Com relação à sexualidade, muda-se da admissão de uma suposta diminuição no interesse e atividade sexual ao longo da vida para uma compreensão do sexo como fonte da juventude e como algo que deve ser buscado insistentemente.

Nesse cenário não se pretende tão somente diagnosticar e tratar doenças, no sentido mais estrito de enfermidades, mas reconhecer capacidades que podem ser sempre melhoradas. Trata-se de um corpo que é pensado como 
funcional e que tem a obrigação moral de bom desempenho. Para se chegar a isso, não somente é válido mas mesmo incentivado que o sujeito seja capaz de manejar os recursos que a ciência provém. Pode-se sugerir que vemos se configurando uma nova concepção de indivíduo e de relação com o corpo que se caracterizaria, em muitas situações, por uma recusa a qualquer tipo de queda no desempenho, a qualquer possibilidade de falha, ou mesmo a qualquer experiência de sofrimento como contingências que também fariam parte da vida. Se até pouco tempo atrás se falava muito em um modelo de indivíduo e de construção de si baseado no autoconhecimento de um sujeito interiorizado e psicologizado, hoje parece que está também emergindo no campo um outro padrão. Também autocentrado, ciente de sua autonomia, preocupado com o seu autodesenvolvimento mas que parece focar sua forma de conhecimento e cuidado de si, incluindo aqui não só a saúde mas a aparência e modelagem corporal, em recursos externos e altamente mediados pela tecnologia. A percepção de suas características e problemas em muito se dá por meio de exames e aparelhagens como as técnicas de imageamento e as dosagens laboratoriais que caracterizam o novo protocolo de diagnóstico. Os recursos terapêuticos acionados também vêm de fora, como a colocação de próteses ou a ingestão de substâncias. Especialmente no caso dos diagnósticos envolvendo sexualidade e envelhecimento, chama ainda mais a atenção a importância atribuída ao uso de medicamentos que permitiriam controlar ou manejar a qualidade das transformações corporais ocorridas com o tempo ou a capacidade sexual.

Especificamente no caso da andropausa, é sintomático que todo o processo de reconhecimento da doença e a promoção do diagnóstico e tratamento se faça tendo como peça-chave a testosterona. Em sintonia com a pregnância do discurso hormonal como fonte explicativa prioritária na medicina desde o século $\mathrm{XX}$, coube à testosterona um papel de destaque já que é o hormônio apresentado como uma espécie de síntese essencial da masculinidade e virilidade. É por meio da configuração de um modelo do aprimoramento externo de si e através do consumo da testosterona que se propagandeará aos homens uma nova capacidade de administração bioquímica do corpo, que lhes garantiria uma fonte inesgotável de renovação da sua própria masculinidade. Pois, como se pôde ver nos discursos que promovem a andropausa, "o homem é mesmo a sua testosterona". 


\section{Referências}

ABDO, C. Estudo populacional do envelhecimento no Brasil. São Paulo: Segmento Farma, 2009.

ABDO, C.; AFIF-ABDO, J. Estudo populacional do envelhecimento (EPE): primeiros resultados masculinos. Revista Brasileira de Medicina, v. 64, n. 8, p. 379-383, 2007.

ANGELL, M. A verdade sobre os laboratórios farmacêuticos. Rio de Janeiro: Record, 2007.

A SAÚDE sexual como portal da saúde do homem. [s.1.]: Bayer Schering Pharma, 2008.

AZIZE, R. Masculinidade, viagra e saúde. Um olhar antropológico. In: RIAL, C. S. M.; TONELI, M. J. F. (Org.). Genealogias do silêncio: feminismo e gênero. Florianópolis: Mulheres, 2004. p. 171-181.

BONACCORSI, A. C. Andropausa: insuficiência parcial androgênica do homem idoso. Uma revisão. Arquivos Brasileiros de Endocrinologia Metabólica, v. 45, n. 2, p. 45-57, 2001.

BRIGEIRO, M. Envelhecimento bem sucedido e sexualidade - relativizando uma problemática. In: BARBOSA, R.; AQUINO E.; HEILBORN, M. L.; BERQUÓ, E. (Org.). Interfaces, gênero, sexualidade e saúde reprodutiva. São Paulo: Ed. Unicamp, 2002. p. 171-206.

BUCHAllA, A. P. O termômetro da vida sexual. Veja, São Paulo, n. 1888, p. 70-78, 19 jan. 2005.

BUCHALlA, A. P. O hormônio da juventude. Veja, São Paulo, n. 1986, p. 116-122, 13 dez. 2006.

CAIROLI, C. E. D. Deficiência androgênica no envelhecimento masculino (DAEM). Revista da AMRIGS, v. 4, n. 48, p. 291-299, 2004.

CARELLI, G. As idades do sexo. Veja, São Paulo, n. 1738, p. 74-79, 13 fev. 2002. 
CARRARA, S.; RUSSO, J.; FARO, L. A política de atenção à saúde do homem no Brasil: os paradoxos da medicalização do corpo masculino. Physis: Revista de Saúde Coletiva, v. 19, n. 3, p. 659-678, 2009.

CASSELS, A.; MOYNIHAN, R. Selling sickness: how the world's biggest pharmaceutical companies are turning us all into patients. New York: Nation Books, 2005.

CONRAD, P. Medicalization and social control. Annual Review of Sociology, n. 18, p. 209-232, 1992.

CONRAD, P. Medicalization of society: on the transformation of human conditions into treatable disorders. Baltimore: The Johns Hopkins University Press, 2007.

CÔRTES, C., RODRIGUES, G., FREITAS JR., O. As fragilidades do homem. Isto é, São Paulo, n. 1908, p. 17 maio 2006.

FISHMAN, J. R. Manufacturing desire: the commodification of female sexual dysfunction. Social Studies of Science, v. 34, n. 2, p. 187-218, 2004.

FLECK, L. Gênesis and development of a scientific fact. Chicago: University of Chicago Press, 1979.

GOMES, R. Sexualidade masculina, gênero e saúde. Rio de Janeiro: Fiocruz, 2008.

HEINEMANN, L. et al. The Aging Male's Syntoms (AMS) scale: update and compilation of international versions. Health and Quality of Life Outcomes, v. 1, n. 15, 1 May 2003.

HEINEMANN, L. et al. Sensitivity as outcome measure of androgen replacement: the AMS scale. Health and Quality of Life Outcomes, v. 4, n. 23, 30 Mar. 2006.

HOBERMAN, J. Testosterone dreams: rejuvenation, aphrodisia, doping. Berkeley: University of California Press, 2005.

KASSIRER, J. On the take: how medicine's complicity with big business can endanger your health. Oxford: Oxford University Press, 2005. 
LATOUR, B. Jamais fomos modernos. Rio de Janeiro: Ed. 34, 1994.

MARINHO, A. Repor testosterona é opção após os 60 anos. $O$ Globo, 10 fev. 2008. Disponível em: <http://70.84.170.34/bolu/ noticias/2008022216205551192189.pdf>. Acesso em: 29 jul. 2010.

MARSHALL, B. Climateric redux?: (re)medicalizing the male menopause. Men and masculinity, n. 9, p. 509-529, 2007.

MARSHALL, B. Science, medicine and virility surveillance: 'sexy seniors' in the pharmaceutical imagination. Sociology of Health \& Illness, v. 32, n. 2, p. 211-224, 2010.

MEDRADO, B. et al. Princípios, diretrizes e recomendações para uma atenção integral aos homens na saúde. Recife: Instituto Papai, 2009.

MEZAROBBA, Glenda. O outono do macho. Veja, São Paulo, n. 1497, p. 90-92, 28 maio 1997.

MINISTÉRIO DA SAÚDE. Deficiência hormonal masculina. [s.d.]. Disponível em: <http://portal.saude.gov.br/portal/saude/visualizar_texto. cfm?idtxt=33345\&janela=1>. Acesso em: 29 jul. 2010.

MORALES, A. et al. Testosterone Deficieny Syndrome (TDS) needs to be named appropriately - the importance of accurate terminology. European Urology, n. 50, p. 407-409, 2006.

MOYNIHAN, R. Female sexual disfunction: merging of marketing and medical science. British Medical Journal, v. 341, p. 698-701, 2010.

NABUCO, C. Andropausa: homens à beira de um ataque de nervos. Claudia, São Paulo, n. 547, p. 154-157, maio 2007.

OUDSHOORN, N. Beyond the natural body, an archeology of sex hormones. London: Routledge, 1994.

PAYER, L. Disease-mongers: how doctors, drug companies, and insures are making you fell sick. New York,:Wiley \& Sons, 1991. 
PURA INVENÇÃO: a andropausa seria apenas uma desculpa para preguiçoso. Veja, São Paulo, n. 1812, p. 64, 23 jul. 2003.

REPOR testosterona é opção após os 60 anos. $O$ Globo, Rio de Janeiro, 10 fev. 2008.

ROHDEN, F. O império dos hormônios e a constituição da diferença entre os sexos. História, ciências, saúde - Manguinhos, v. 15, p. 133-152, 2008.

ROHDEN, F.. Diferenças de gênero e medicalização da sexualidade na criação do diagnóstico das disfunções sexuais. Estudos Feministas, v. 17, n. 1, p. 89-109, 2009.

ROSENBERG, C. E. The tyranny of diagnosis: specific entities and individual experience. The Milbank Quartely, v. 80, n. 2, p. 237-259, 2002.

ROSENFELD, D.; FAIRCLOTH, C. A. Medicalized masculinities. Philadelphia: Temple University Press, 2006.

SCHRAIBER, L. B., GOMES, R.; COUTO, M. T. Homens e saúde na pauta da Saúde Coletiva. Ciência e Saúde Coletiva, v. 10, n. 1, p. 7-17, jan./mar. 2005.

SENNA, R. A. de M. Passagens de idade: uma análise antropológica sobre as articulações entre o saber biomédico e o saber leigo no discurso de mulheres de camadas médias. Tese (Doutorado em Saúde Coletiva)-IMS, Universidade do Estado do Rio de Janeiro, Rio de Janeiro, 2009.

TIEFER, L. Female sexual dysfunction: a case study of disease mongering and activist resistance. Plosmedicine, v. 3, n. 4, p. 1-5, 2006.

VEJA: Especial Homem. São Paulo, out. 2003. Número especial.

Recebido em: 05/10/2010

Aprovado em: 01/02/2011 